Short Communication

\title{
Renovation of Lithium Cobalt Oxide from Spent Lithium Ion Batteries by an Aqueous Pulsed Discharge Plasma
}

\author{
Shuguang Zhu ${ }^{1,2, *}$, Ying Qin ${ }^{1}$, Jin Zhang ${ }^{1}$ \\ ${ }^{1}$ Anhui Advanced Technology Research Institute of Green Building, Anhui Jianzhu University, Hefei \\ 230601, China \\ ${ }^{2}$ Shanghai Cooperative Centre for WEEE Recycling, Shanghai Second Polytechnic University, \\ Shanghai 201209, China \\ *E-mail: 286537056@qq.com
}

doi: $10.20964 / 2016.07 .103$

Received: 28 January 2016 / Accepted: 11 March 2016 / Published: 4 June 2016

\begin{abstract}
Used $\mathrm{LiCoO}_{2}$ cathode material in spent lithium ion batteries was renovate in $0.1 \mathrm{M} \mathrm{LiOH}$ solution using aqueous pulsed discharge plasma for $30 \mathrm{~min}$, in which aqueous pulsed discharge plasma was used for the first time as an alternative process to renovate its electrochemical characteristics. After treatment, the microstructure of spent and renovated $\mathrm{LiCoO}_{2}$ has been studied by Raman spectroscopy, and the results obtained were compared with those by XRD and SEM, respectively. Experimental results showed that electrohydraulic cavitation could be effectively used to remove organic substance stuck on $\mathrm{LiCoO}_{2}$ surface and facilitate the ordered crystalline layer compound processes. The validity of the process has been evaluated by electrochemical test. Its charge capacity was $132.9 \mathrm{mAh} \mathrm{g}^{-1}$ in the first cycle and the discharge capacity was $126.7 \mathrm{mAh} \mathrm{g}^{-1}$, which was retained $97.2 \%$ after 50 cycles.
\end{abstract}

Keywords: Spent lithium-ion batteries; $\mathrm{LiCoO}_{2}$; aqueous pulsed discharge plasma; renovation

\section{FULL TEXT}

(C) 2016 The Authors. Published by ESG (www.electrochemsci.org). This article is an open access article distributed under the terms and conditions of the Creative Commons Attribution license (http://creativecommons.org/licenses/by/4.0/). 